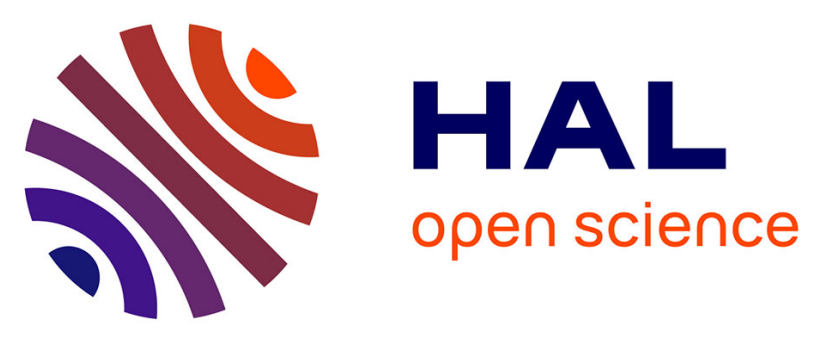

\title{
Porous Mn-doped $\mathrm{ZnO}$ nanoparticles for enhanced solar and visible light photocatalysis
}

Faouzi Achouri, Serge Corbel, Lavinia Balan, Kevin Mozet, Emilien Girot, Ghouti Medjahdid, Myriam Ben Said, Ahmed Ghrabi, Raphael Schneider

\section{- To cite this version:}

Faouzi Achouri, Serge Corbel, Lavinia Balan, Kevin Mozet, Emilien Girot, et al.. Porous Mn-doped $\mathrm{ZnO}$ nanoparticles for enhanced solar and visible light photocatalysis. Materials \& Design, 2016, 101, pp.309-316. 10.1016/j.matdes.2016.04.015 . hal-01303879

\section{HAL Id: hal-01303879 \\ https://hal.science/hal-01303879}

Submitted on 24 Feb 2020

HAL is a multi-disciplinary open access archive for the deposit and dissemination of scientific research documents, whether they are published or not. The documents may come from teaching and research institutions in France or abroad, or from public or private research centers.
L'archive ouverte pluridisciplinaire HAL, est destinée au dépôt et à la diffusion de documents scientifiques de niveau recherche, publiés ou non, émanant des établissements d'enseignement et de recherche français ou étrangers, des laboratoires publics ou privés.

\section{(ㅇ)(1) $\$$}

Distributed under a Creative Commons Attribution - NonCommercial - NoDerivatives| 4.0 


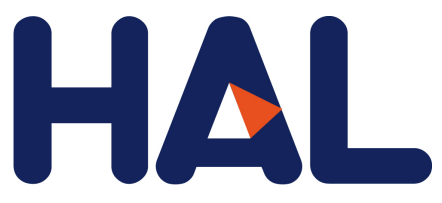

archives-ouvertes

\section{Porous Mn-doped $\mathrm{ZnO}$ nanoparticles for enhanced solar and visible light photocatalysis}

Faouzi Achouri, Serge Corbel, Lavinia Balan, Kevin Mozet, Emilien Girot, Ghouti Medjahdid, Myriam Ben Said, Ahmed Ghrabi, Raphael Schneider

\section{To cite this version:}

Faouzi Achouri, Serge Corbel, Lavinia Balan, Kevin Mozet, Emilien Girot, et al.. Porous Mn-doped $\mathrm{ZnO}$ nanoparticles for enhanced solar and visible light photocatalysis. Materials and Design, Elsevier, 2016, 101, pp.309-316. 10.1016/j.matdes.2016.04.015 . hal-01303879

\section{HAL Id: hal-01303879 \\ https://hal.archives-ouvertes.fr/hal-01303879}

Submitted on 24 Feb 2020

HAL is a multi-disciplinary open access archive for the deposit and dissemination of scientific research documents, whether they are published or not. The documents may come from teaching and research institutions in France or abroad, or from public or private research centers.
L'archive ouverte pluridisciplinaire HAL, est destinée au dépôt et à la diffusion de documents scientifiques de niveau recherche, publiés ou non, émanant des établissements d'enseignement et de recherche français ou étrangers, des laboratoires publics ou privés.

\section{(1) (1) $\$$}

Distributed under a Creative Commons Attribution - NonCommercial - NoDerivatives| 4.0 


\title{
Porous Mn-doped ZnO nanoparticles for enhanced solar and visible light photocatalysis
}

\author{
Faouzi Achouri a,b,c , Serge Corbel ${ }^{\mathrm{a}}$, Lavinia Balan ${ }^{\mathrm{d}}$, Kevin Mozet ${ }^{\mathrm{a}}$, Emilien Girot ${ }^{\mathrm{a}}$, Ghouti Medjahdi ${ }^{\mathrm{e}}$, \\ Myriam Ben Said ${ }^{\text {b }}$, Ahmed Ghrabi ${ }^{\text {b }}$, Raphaël Schneider ${ }^{\mathrm{a}, *}$ \\ a Université de Lorraine, Laboratoire Réactions et Génie des Procédés (LRGP), UMR 7274, CNRS, 1 Rue Grandville, BP 20451, 54001 Nancy Cedex, France \\ b Centre de Recherches et Technologies des Eaux (CERTE), Laboratoire Eaux Usées et Environnement, P.O. Box 273, 8020, Soliman, Tunis, Tunisia \\ ' Université de Carthage, Faculté des Sciences de Bizerte, 7021, Jarzouna, Bizerte, Tunisia \\ d Institut de Science des Matériaux de Mulhouse (IS2M), LRC 7228, 15 Rue Jean Starcky, 68093 Mulhouse, France \\ e Institut Jean Lamour (IJL), Université de Lorraine, CNRS, UMR 7198, CNRS, BP 70239, 54506 Vandoeuvre-lès-Nancy Cedex, France
}

\section{A R T I C L E I N F O}

Article history:

Received 9 February 2016

Received in revised form 4 April 2016

Accepted 5 April 2016

Available online 9 April 2016

Keywords:

Mn-doped ZnO

Porous nanoparticles

Photocatalysis

Oxidation

\begin{abstract}
A B S T R A C T
Porous $\mathrm{Mn}$-doped $\mathrm{ZnO}$ (ZnO:Mn) nanoparticles with an average diameter of ca. $21 \mathrm{~nm}$ were prepared by a simple and cheap solvothermal process involving no templates, post-synthetic annealing or etching. The particles produced were characterized by XRD, Raman spectroscopy, SEM, TEM, XPS, diffuse reflectance spectroscopy and BET surface area measurements and the effects of $\mathrm{Mn}^{2+}$-doping on the structural, optical and photocatalytic properties of $\mathrm{ZnO}$ particles were investigated. The particles doped with $3 \mathrm{~mol} \% \mathrm{Mn}^{2+}$ were found to exhibit the highest catalytic activity toward the photodegradation of the Orange II dye under solar light irradiation. Our results demonstrate that $\mathrm{Mn}^{2+}$-doping shifts the optical absorption to the visible region, increases the specific surface area of the photocatalyst and reduces the recombination of electron-hole pairs. The influence of various operational parameters (amount of catalyst, concentration of dye and $\mathrm{pH}$ ) on the photodegradation and the photocatalytic mechanism were studied. Finally, we demonstrated that the ZnO:Mn photocatalyst is stable and can be easily recycled up to ten times without any significant decrease in photocatalytic activity.
\end{abstract}

\section{Introduction}

The photocatalytic degradation of organic pollutants like dyes or pesticides from water using semiconductor materials has recently attracted a lot of attention [1-3]. Among photocatalysts, zinc oxide $\mathrm{ZnO}$ is a promising material either for the generation of hydrogen or for decomposition of organics owing to its large exciton binding energy (60 $\mathrm{meV}$ ) at room temperature, high photosensitivity, low cost, high chemical stability and weak toxicity [4-7]. However, the wide bandgap of $\mathrm{ZnO}(3.37 \mathrm{eV}$ ) limits its response to the UV light only, leaving 95-97\% energy of the whole solar spectrum unusable. Moreover, due to the very fast recombination of photogenerated electron $\left(\mathrm{e}^{-}\right) /$hole $\left(\mathrm{h}^{+}\right)$pairs, surface reactions that generate the reactive oxygen species (ROS) like hydroxyl $\bullet \mathrm{OH}$ or superoxide $\mathrm{O}_{2}{ }^{-}$radicals and $\mathrm{H}_{2} \mathrm{O}_{2}$ responsible for the catalytic photodegradation cannot optimally occur.

In recent years, a variety of effective approaches like semiconductor coupling $[6,8,9]$ or doping [10-13] have been developed to modify ZnO in order to improve its photoresponse capability. Doping, which consists in the intentional incorporation of impurities into the host lattices, is the most commonly used method to tune the optical and chemical

\footnotetext{
* Corresponding author.

E-mail address: raphael.schneider@univ-lorraine.fr (R. Schneider).
}

properties of nanomaterials $[14,15]$. Because $\mathrm{Mn}^{2+}$ doping generates new energy states within the bandgap of $\mathrm{ZnO}$ [16-22], Mn-doped $\mathrm{ZnO}$ (ZnO:Mn) particles were recently found to be efficient for solar or visible-light driven photocatalysis for two reasons. First, because this doping enhances the absorption in the visible region. Second, because the new energy states act as intermediate steps for $\mathrm{e}^{-}$in their transitions between the valence and the conduction bands and thus efficiently promote the separation of photogenerated $\mathrm{e}^{-}$and $\mathrm{h}^{+}$. All studies clearly demonstrated that ZnO:Mn particles exhibit a higher photocatalytic activity than $\mathrm{ZnO}$ under UV or visible light irradiation and that the morphology, the size, the defect concentrations and the level of doping play crucial roles on the photodegradation efficiency of various organic dyes like methyl orange or methylene blue [16-22].

Porous $\mathrm{ZnO}$ materials have also gained much attention recently owing to their superior photocatalytic properties compared to $\mathrm{ZnO}$ particles [23-27]. Since the contaminant molecules need to be adsorbed on the photocatalyst surface for the redox reactions to occur, a high effective surface area associated to the high diffusivity of contaminants will give enhanced photocatalytic activity [28]. Up to now, several methods such as hydrolysis of $\mathrm{Zn}(\mathrm{OAc})_{2}$ followed by high temperature annealing $[29,30]$, hydrothermal synthesis followed by etching [31], amino acidassisted synthesis [32] or hydrolysis of $\mathrm{Zn}(\mathrm{OAc})_{2}$ in the presence of templates (starch, polystyrene, gelatin, ...) followed by calcination [33-37] 
have been developed to obtain porous $\mathrm{ZnO}$ particles. However, most of these preparation methods are often faced with problems such as high temperature or tedious procedures. In this paper, we report a facile method for the preparation of porous Mn-doped $\mathrm{ZnO}$ particles via a solvothermal process. The high photocatalytic activity of $\mathrm{ZnO}: \mathrm{Mn}$ particles for the degradation of Orange II under solar light irradiation was further demonstrated.

\section{Experimental section}

\subsection{Materials}

$\mathrm{Zn}(\mathrm{OAc})_{2} \cdot 2 \mathrm{H}_{2} \mathrm{O}\left(>98 \%\right.$, Sigma), $\mathrm{Mn}(\mathrm{OAc})_{2} \cdot 4 \mathrm{H}_{2} \mathrm{O}$ (99.99\%, Sigma), Orange II sodium salt (>85\%, Sigma), sodium hydroxide $(>97 \%$, Sigma), and anhydrous ethanol were used as received without further purification. All solutions were prepared using Milli-Q water $(18.2 \mathrm{M} \Omega \cdot \mathrm{cm}$, Millipore) as solvent.

\subsection{Preparation of $\mathrm{ZnO}$ and $\mathrm{Mn}$-doped $\mathrm{ZnO}$ particles}

$\mathrm{ZnO}$ particles were synthesized by a solvothermal method based on the hydrolysis of $\mathrm{Zn}(\mathrm{OAc})_{2}$. Typically, in a three-necked flask equipped with a condenser and a dropping funnel, $\mathrm{Zn}(\mathrm{OAc})_{2} \cdot 2 \mathrm{H}_{2} \mathrm{O}(511 \mathrm{mg}$, $2.33 \mathrm{mmol}$ ) was dissolved in $35 \mathrm{~mL}$ ethanol. To this solution, $\mathrm{NaOH}$ (96 mg, $2.33 \mathrm{mmol}$ ) in $35 \mathrm{~mL}$ ethanol was added dropwise and the mixture stirred for $30 \mathrm{~min}$ at room temperature. Then, the solution was transferred into a $140 \mathrm{~mL}$ Teflon-sealed autoclave and was heated at $160{ }^{\circ} \mathrm{C}$ for $24 \mathrm{~h}$. After cooling to room temperature, the $\mathrm{ZnO}$ particles were collected by centrifugation, washed three times with water, one time with ethanol, and dried at $70{ }^{\circ} \mathrm{C}$ overnight.

$\mathrm{Mn}$-doped $\mathrm{ZnO}$ particles were prepared using a similar synthetic procedure. For the particles doped with $3 \% \mathrm{Mn}, \mathrm{Zn}(\mathrm{OAc})_{2} \cdot 2 \mathrm{H}_{2} \mathrm{O}$ (496 mg, $2.259 \mathrm{mmol}$ ) and $\mathrm{Mn}(\mathrm{OAc})_{2} \cdot 4 \mathrm{H}_{2} \mathrm{O}(17 \mathrm{mg}, 0.069 \mathrm{mmol})$ were used. The purification and drying procedures are similar to those previously described for $\mathrm{ZnO}$ particles.

\subsection{Photocatalytic degradation of Orange II}

The photocatalytic activity was evaluated by the degradation of an aqueous solution of Orange II $(10 \mathrm{mg} / \mathrm{L})$ at room temperature under solar light irradiation. In a typical experiment, the $\mathrm{ZnO}: \mathrm{Mn}$ nanoparticles $(60 \mathrm{mg}$ ) were dispersed in $30 \mathrm{~mL}$ Orange II aqueous solution $(10 \mathrm{mg} / \mathrm{L})$ and the suspension was magnetically stirred under ambient conditions for $60 \mathrm{~min}$ in the dark to reach an adsorption-desorption equilibrium. Under stirring, the suspension was exposed to simulated solar light irradiation produced by Sylvania LuxLine FHO T5 neon tubes. The light intensity was estimated to be $5.5 \mathrm{~mW} / \mathrm{cm}^{2}$. At certain time intervals, $1 \mathrm{~mL}$ of the suspension was extracted and centrifuged (15,000 rpm for $2 \mathrm{~min}$ ) to remove the photocatalyst. The degradation process was monitored by measuring the absorption of Orange II at $485 \mathrm{~nm}$ using a UV-visible absorption spectrometer. The visible light irradiation was carried out using the neon tubes previously described and a polycarbonate film was used as the UV cutoff filter.

\subsection{Quantification of hydroxyl radical production. DST assays}

The production of $\bullet \mathrm{OH}$ radicals by $\mathrm{ZnO}$ and $\mathrm{ZnO}: \mathrm{Mn}$ particles was estimated using disodium terephthalate (DST), which turns into fluorescent 2-hydroxyterephthalate, 2-OH-DST ( $\lambda_{\mathrm{em}}=428 \mathrm{~nm}$ ) upon reaction with $\bullet \mathrm{OH}$ radicals [38-40]. Briefly, $5 \mathrm{mg}$ of $\mathrm{ZnO}$ or $\mathrm{ZnO}: \mathrm{Mn}$ particles were dispersed by magnetic stirring in $100 \mathrm{~mL}$ water. Next, $1 \mathrm{~mL}$ of this dispersion was mixed with $1 \mathrm{~mL}$ of DST $(0.1 \mathrm{M}$ in water) before being irradiated with a $\mathrm{Hg}$-Xe lamp (light intensity = $200 \mathrm{~mW} \cdot \mathrm{cm}^{-2}$ ) for various times. The mixture was then treated with $1 \mathrm{~mL}$ of $1 \mathrm{M} \mathrm{NaOH}$ and incubated for $50 \mathrm{~min}$ at room temperature before filtration on $0.2 \mu \mathrm{m}$ polyvinylidene fluoride Acrodisc Syringe Filter. The photoluminescence spectra were recorded to estimate 2-OH-DST formed $\left(\lambda_{\mathrm{ex}}=300 \mathrm{~nm}\right)$. Control samples were (i) DST irradiated in the absence of particles and (ii) DST and particles but without light activation. PL intensities measured after these control experiments were subtracted from those measured when the particles were irradiated in the presence of DST.

\subsection{Characterization}

Transmission electron microscopy (TEM) images were taken by placing a drop of the particles dispersed in methanol onto a carbon film-supported copper grid. Samples were studied using a Philips CM200 instrument operating at $200 \mathrm{kV}$. Scanning electron microscopy (SEM) pictures were prepared using JEOL Scanning Electron Microscope JSM-6490 LV. The X-ray powder diffraction (XRD) diagrams of all samples were measured using Panalytical X'Pert Pro MPD diffractometer using $\mathrm{Cu} \mathrm{K} \alpha$ radiation. The X-ray powder diffraction data were collected from an X'Pert MPD diffractometer (PANalytical AXS) with a goniometer radius $240 \mathrm{~mm}$, fixed divergence slit module $\left(1 / 2^{\circ}\right.$ divergence slit, 0.04 rd Sollers slits) and an X'Celerator as a detector. The powder samples were placed on a silicon zero-background sample holder and the XRD patterns were recorded at room temperature using $\mathrm{Cu} \mathrm{K}_{\mathrm{o}}$ radiation ( $\lambda=0.15418 \mathrm{~nm}$ ). X-ray photoelectron spectroscopy (XPS) analyses were performed on a Gammadata Scienta (Uppsala, Sweden) SES 200-2 spectrometer under ultra-high vacuum $\left(P<10^{-9} \mathrm{mbar}\right)$. The measurements were performed at normal incidence (the sample plane is perpendicular to the emission angle). The spectrometer resolution at the Fermi level is about $0.4 \mathrm{eV}$. The depth analyzed extends up to about $8 \mathrm{~nm}$. The monochromatized AlK $\alpha$ source $(1486.6 \mathrm{eV})$ was operated at a power of $420 \mathrm{~W}(30 \mathrm{~mA}$ and $14 \mathrm{kV})$ and the spectra were acquired at a take-off angle of $90^{\circ}$ (angle between the sample surface and photoemission direction). During acquisition, the pass energy was set to $500 \mathrm{eV}$ for wide scans and to $100 \mathrm{eV}$ for high-resolution spectra. CASAXPS software (Casa Software Ltd, Teignmouth, UK, www. casaxps.com) was used for all peak fitting procedures and the areas of each component were modified according to classical Scofield sensitivity factors.

The textural properties of the materials were investigated with a Micromeritics 3Flex Surface Characterization Analyzer instrument using liquid nitrogen $\left(-196{ }^{\circ} \mathrm{C}\right)$. Prior to the analyses, the samples were out-gassed overnight under primary vacuum at $40{ }^{\circ} \mathrm{C}$ on the ports of the Micromeritics VacPrep 061 degasser followed by 4 h out-gassing under high vacuum on the analyse ports. The resulting isotherms were analysed using the BET (Brunauer-Emmett-Teller) method.

All the optical measurements were performed at room temperature $\left(20 \pm 1^{\circ} \mathrm{C}\right)$ under ambient conditions. Absorption spectra of liquid samples were recorded on a Thermo Scientific Evolution 220 UV-visible spectrophotometer. The diffuse reflectance absorption spectra (DRS) were recorded on a Shimadzu 2600 UV-visible spectrophotometer. $\mathrm{BaSO}_{4}$ powder was used as a standard for baseline measurements and spectra were recorded in a range of $250-1400 \mathrm{~nm}$. Raman spectra were recorded using a Xplora spectrometer from Horiba Scientific with $532 \mathrm{~nm}$ wavelength incident YAG laser light.

\section{Results and discussion}

\subsection{Synthesis and characterization of photocatalysts}

Fig. 1 shows the powder XRD patterns of $\mathrm{ZnO}$ particles when varying the molar dopant percentage in $\mathrm{Mn}^{2+}$ from 0 to 7 . All diffraction peaks could be indexed to the standard hexagonal wurtzite structure of $\mathrm{ZnO}$ (space group $P 6_{3} m c$, JCPDS No 36-1451, a = 3.250 Å, $c=5.207 \AA$ ). The diffraction peaks were sharp, indicating the high crystallinity of the materials produced. Although the ionic radius of $\mathrm{Mn}^{2+}(0.80 \AA)$ is larger than that of $\mathrm{Zn}^{2+}(0.74 \AA)$, no significant distortion in the lattice structure was observed. No impurity phase attributed to manganese 


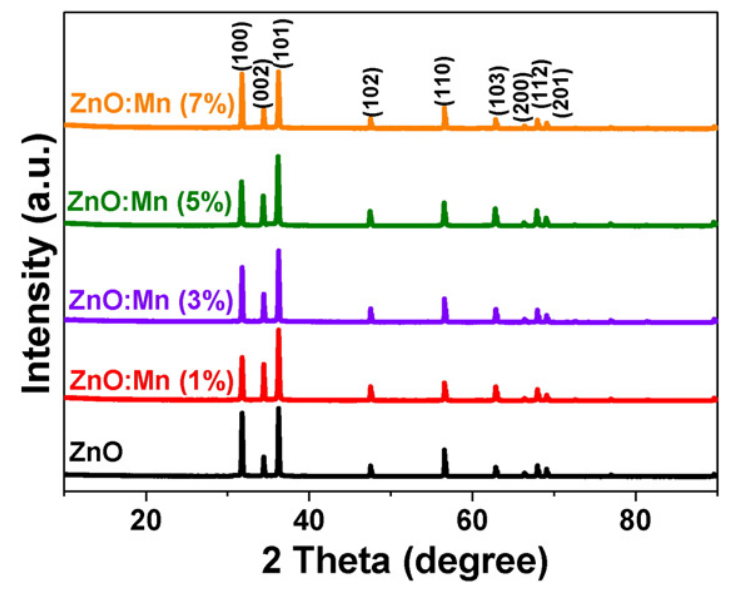

Fig. 1. XRD patterns of $\mathrm{ZnO}$ and $\mathrm{Mn}$-doped $\mathrm{ZnO}$ particles.

oxides could be detected, indicating that $\mathrm{Mn}^{2+}$ was completely doped into the $\mathrm{ZnO}$ crystal lattice.

The wurtzite crystal structure of $\mathrm{ZnO}$ particles was further confirmed by Raman spectroscopy (Fig. 2). The peaks located at 330, 378, 410 and $436 \mathrm{~cm}^{-1}$ can be assigned to $E_{2}, A_{1 T O}, E_{1}$, and $E_{2}$ (high) vibration modes of $\mathrm{ZnO}$ with $\mathrm{P}_{3} \mathrm{mc}$ symmetry, respectively [41]. Well-resolved peaks originating from multiphonon processes could also be observed at 206 and between 1030 and $1200 \mathrm{~cm}^{-1}$. XRD and Raman analyses demonstrate that $\mathrm{ZnO}: \mathrm{Mn}$ particles produced are composed of hexagonal $\mathrm{ZnO}$ with good crystal quality.

Fig. S1 shows SEM images of $\mathrm{ZnO}$ nanoparticles and of the $\mathrm{ZnO}$ sample doped with $3 \% \mathrm{Mn}^{2+}$. Both samples assemble into microparticles of globular morphology that are more homogeneous in size for the doped nanoparticles. Numerous pores can be seen in the $\mathrm{ZnO}$ and $\mathrm{ZnO}: \mathrm{Mn}$ materials which should be beneficial to increase the contact area for reactant diffusivity and for enhanced photocatalytic activity [42]. The energy dispersive X-ray (EDX) spectrum of the ZnO:Mn (3\%) sample only show peaks corresponding to $\mathrm{Zn}, \mathrm{O}$, and $\mathrm{Mn}$ and no trace amount of impurities could be seen in the detection limit of the EDX analysis (Fig. S2). Quantitative analysis shows that the concentration of $\mathrm{Mn}^{2+}$ in the $3 \%$ atomic $\mathrm{Mn}$-doped $\mathrm{ZnO}$ particles is $2.2 \%$, indicating that the amount of $\mathrm{Mn}$ incorporated into the $\mathrm{ZnO}$ lattice is slightly lower than the nominal amount of Mn used during the synthesis. To obtain more details about the structures of these materials, TEM and HR-TEM experiments were conducted (Fig. 3 ). The $\mathrm{ZnO}$ sample is mainly composed of spherical/ellipsoidal nanoparticles with an average diameter of $28 \mathrm{~nm}$ (Fig. 3a). A few particles with hexagonal morphology can also be observed. A decrease in nanoparticles size to ca. $21 \mathrm{~nm}$ was observed for

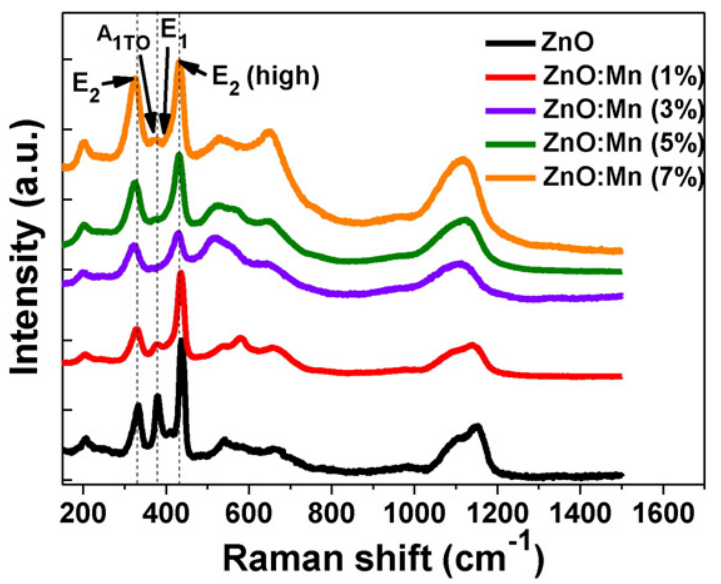

Fig. 2. Room temperature Raman spectra of $\mathrm{ZnO}$ and $\mathrm{Mn}$-doped $\mathrm{ZnO}$ nanoparticles.
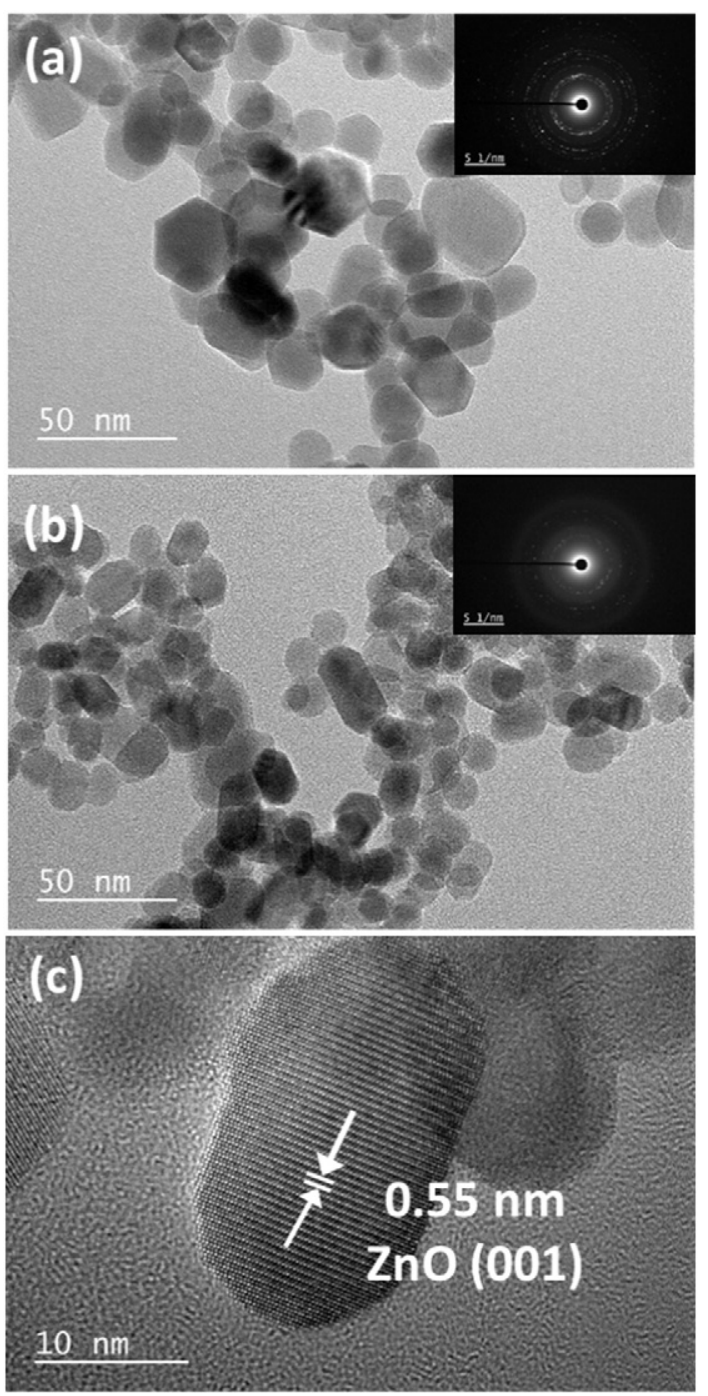

Fig. 3. TEM images of (a) $\mathrm{ZnO}$ and (b) $\mathrm{ZnO}: \mathrm{Mn}$ (3\%) nanoparticles (the inserts are the SAED patterns). (c) HR-TEM micrograph of ZnO:Mn (3\%) particles.

ZnO:Mn (3\%) particles (Fig. 3b). This decrease may be attributed to the growth inhibition of the nanocrystals originating from the presence of dopant ions in the reaction medium $[43,44]$. The smaller size of ZnO:Mn particles should be beneficial for photocatalytic activity. The selected area electron diffraction (SAED) patterns (insets of Fig. 3a-b) show a set of concentric reflexes, indicating the hexagonal structure of the $\mathrm{ZnO}$ particles prepared. This was further confirmed by a HR-TEM image of $\mathrm{ZnO}: \mathrm{Mn}$ particles which shows clear lattice fringes with d-spacing of $0.55 \mathrm{~nm}$, value consistent with the distance between two (001) crystal planes of hexagonal ZnO (Fig. 3c).

Further characterization studies using XPS provided evidences for the surface states and composition and the results obtained with $\mathrm{ZnO}$ doped with $3 \% \mathrm{Mn}^{2+}$ are shown in Fig. 4. Fig. 4a shows the survey scan of the sample where the presence of $\mathrm{Zn}, \mathrm{O}$ and $\mathrm{Mn}$ is evident. The spectrum also shows the signal of $\mathrm{Na}$ which originates from $\mathrm{NaOH}$ used for the synthesis. The fine XPS spectra show that the $\mathrm{Zn} 2 \mathrm{p}_{3 / 2}$ signal appears at $1021.46 \mathrm{eV}$, which corresponds to $\mathrm{Zn}-\mathrm{O}$ bonds in the $\mathrm{ZnO}$ lattice (Fig. $4 \mathrm{~b}$ ). For Mn $2 \mathrm{p}_{3 / 2}$, the energy of the

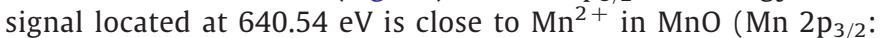
$640.7 \mathrm{eV}$ ). The signals observed at 641.51 and $642.44 \mathrm{eV}$ could be assigned to $\mathrm{Mn}_{2} \mathrm{O}_{3}$ and $\mathrm{MnO}_{2}$, respectively, indicating the presence of $\mathrm{Mn}$ oxides associated $\mathrm{Mn}$-doped $\mathrm{ZnO}$ and/or the incorporation of $\mathrm{Mn}$ ions in the $\mathrm{ZnO}$ lattice in the +3 or +4 oxidation states. The latter hypothesis is supported by recent reports $[45,46]$. Finally, 

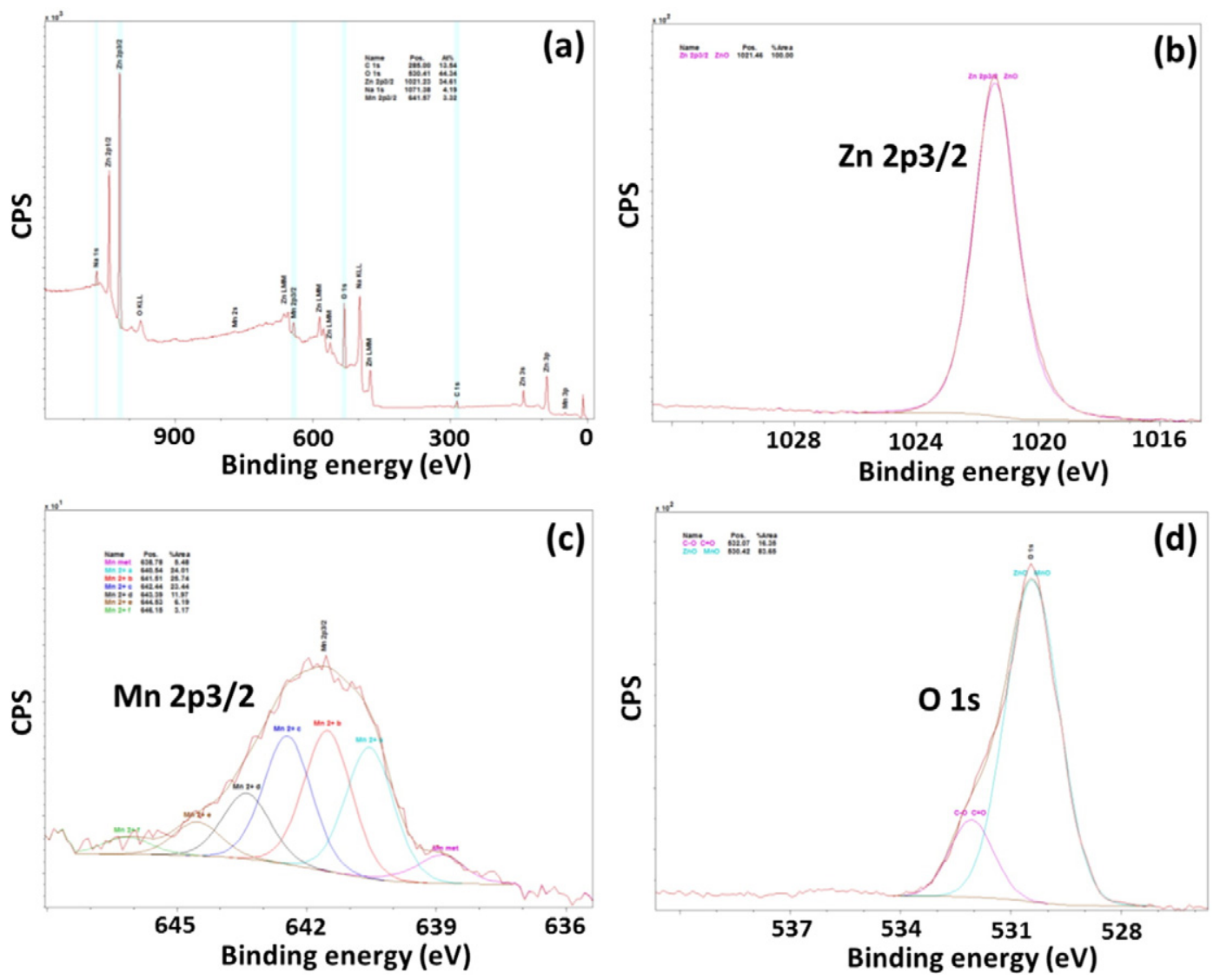

Fig. 4. (a) XPS survey scan for ZnO:Mn (3\%) particles. (b-d) High resolution peaks for Zn 2p, Mn 2p, and O 1s, respectively.

Fig. 4d shows the high resolution signal for the 01 s orbital. The broad peak is due to the surface-adsorbed $\mathrm{OH}^{-}$ions on $\mathrm{ZnO}$ particles. The high intensity peak located at the lower binding energy side is associated to $\mathrm{Zn}-\mathrm{O}$ or $\mathrm{Mn}-\mathrm{O}$ bonds.

The optical properties of undoped and Mn-doped $\mathrm{ZnO}$ samples were further analyzed by UV-visible absorption and diffuse reflectance spectroscopy (DRS). ZnO shows a sharp near band edge absorption at ca. $380 \mathrm{~nm}$ due to its bandgap of $3.3 \mathrm{eV}$. After $\mathrm{Mn}^{2+}$ doping, the absorption markedly increases in the visible region (Fig. S3). ZnO particles exhibit the highest reflectance throughout the whole visible region while the reflectance decreases with the increase of $\mathrm{Mn}^{2+}$ doping in the visible region (Fig. 5), indicating that $\mathrm{ZnO}: \mathrm{Mn}$ particles

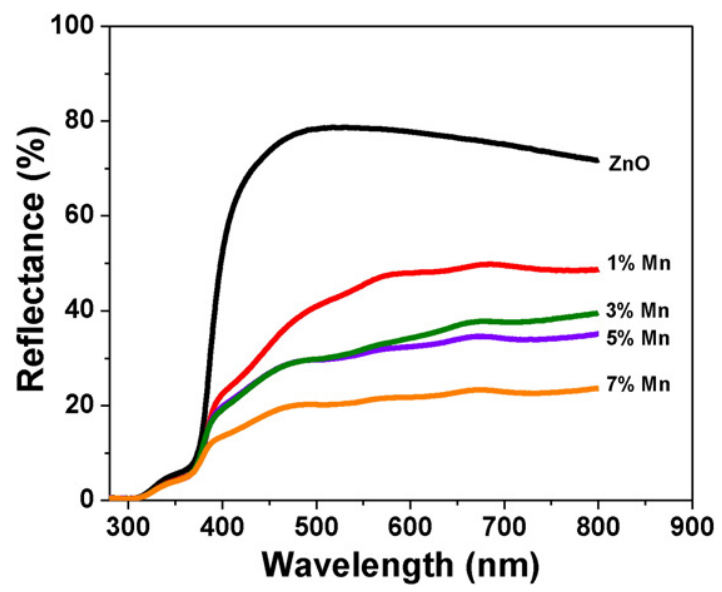

Fig. 5. Room temperature UV-visible diffuse reflectance spectra of $\mathrm{ZnO}$ and $\mathrm{Mn}^{2+}$-doped $\mathrm{ZnO}$ particles. should be better photocatalysts under solar and visible light irradiation. The bandgap values were determined from DRS spectra by converting the absolute reflection to the Kubelka-Munk function $\left(\mathrm{F}_{\mathrm{KM}}\right)$ and were found to gradually decrease from 3.06 for $\mathrm{ZnO}$ to $2.83 \mathrm{eV}$ for $\mathrm{ZnO}: \mathrm{Mn}$ (7\%) (Fig. S4). This decrease originates from the formation of various optically active sub-levels through the bandgap of $\mathrm{ZnO}$, resulting in a decrease in its optical bandgap. Finally, no fluorescence signal was observed for all Mn-doped samples after excitation at $300 \mathrm{~nm}$. This indicates that the electron-hole recombination is completely inhibited through the $\mathrm{Mn}^{2+}$ doping and the presence of a large number of carrier traps within the nanoparticles.

\subsection{Photocatalytic activity}

The photocatalytic performances of ZnO:Mn particles have been evaluated for the degradation of Orange II $(10 \mathrm{mg} / \mathrm{L})$ and compared with $\mathrm{ZnO}$ particles under solar light irradiation $\left(5.5 \mathrm{~mW} / \mathrm{cm}^{2}\right)$. In preliminary experiments conducted in the absence of the photocatalyst, no significant photolysis of the dye was observed during $6 \mathrm{~h}$ of irradiation. Once the catalyst added, the photodegradation was monitored by the time dependent UV-visible spectral changes of Orange II in the presence of $\mathrm{ZnO}$ and $\mathrm{ZnO}: \mathrm{Mn}$ catalysts (Fig. 6). Using the $\mathrm{ZnO}: \mathrm{Mn}$ (3\%) catalyst, the characteristic peak at $485 \mathrm{~nm}$ gradually decreases with irradiation time and disappears completely after $210 \mathrm{~min}$, suggesting the complete photodegradation (Fig. 6b). All other photocatalysts exhibited a weaker activity. The results described in Fig. 6a also demonstrate that when the doping in $\mathrm{Mn}^{2+}$ is higher that the optimal value (3\%), $\mathrm{Mn}^{2+}$ ions probably act as electron and holes recombination centers and hence decrease the photocatalytic activity.

We also evaluated the photodegradation of Orange II under visible irradiation using a light intensity of $15 \mathrm{~mW} / \mathrm{cm}^{2}$ (Fig. S5). Results obtained showed that the mineralization of the dye could be achieved 

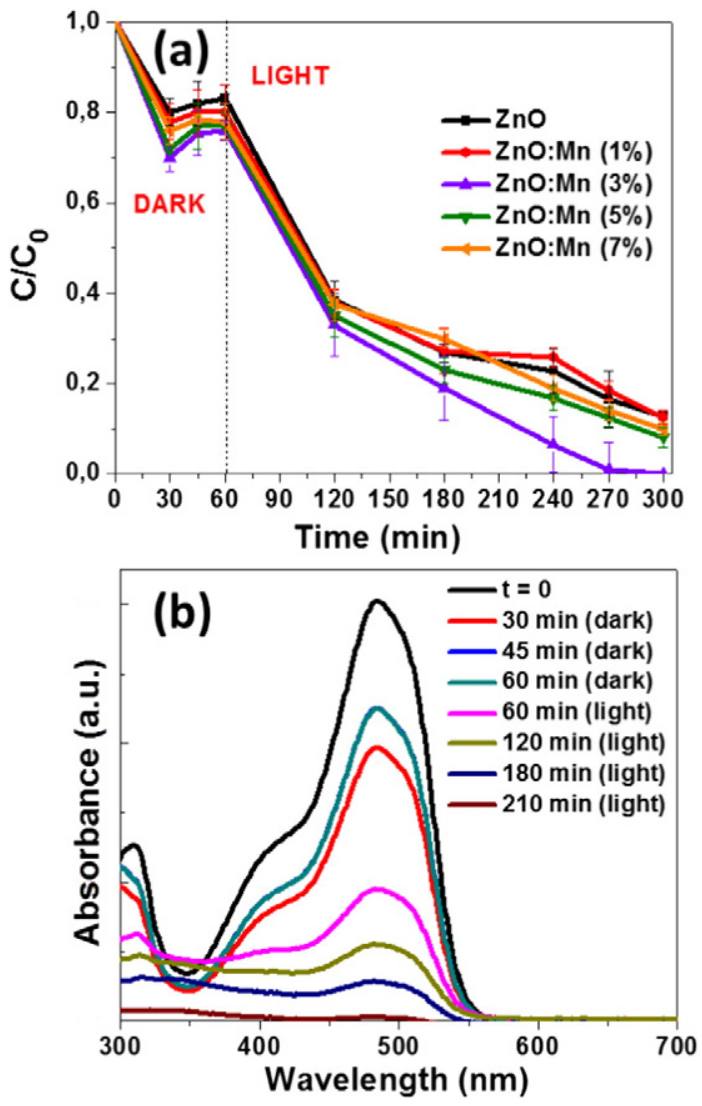

Fig. 6. (a) Influence of the $\mathrm{Mn}$ doping of $\mathrm{ZnO}$ nanoparticles for the degradation of Orange II in aqueous solution ( $C$ is the Orange II concentration at time $t$, and $C_{0}$ is the concentration of the dye at $t=0$; Volume of solution, $30 \mathrm{~mL}$; Mass of photocatalyst, $60 \mathrm{mg}$; Orange II concentration, $10 \mathrm{mg} / \mathrm{L}$ ). (b) Variation of Orange II concentration as a function of irradiation time using the $\mathrm{ZnO}: \mathrm{Mn}(3 \%)$ photocatalyst.

(ca. $75 \%$ of degradation after $240 \mathrm{~min}$ ) but required a longer time than under solar irradiation (near complete photodegradation after 210 min illumination).

\subsection{Effect of catalyst dosage, of Orange II concentration and of $\mathrm{pH}$}

The effect of the catalyst amount on the photodegradation of Orange II under simulated solar light was studied by varying the $\mathrm{ZnO}: \mathrm{Mn}(3 \%)$ catalyst concentration from 0.5 to $3.0 \mathrm{~g} / \mathrm{L}$ (Fig. 7a). From 0.5 to $2.0 \mathrm{~g} / \mathrm{L}$ of catalyst, the photodegradation rates increase with the catalyst amount. The initial rate constants given by the slope at the initial time of irradiation are $0.004,0.005,0.007,0.017$ and $0.006 \mathrm{~min}^{-1}$ for 0.5 , $1.0,1.5,2.0 \mathrm{~g} / \mathrm{L}$ and $3 \mathrm{~g} / \mathrm{L}$ of catalyst, respectively. Since the adsorption phase is not markedly influenced by the amount of catalyst used, the increase of the photodegradation rate when increasing the amount of catalyst probably originates from the increase of the surface illuminated during photocatalytic experiments. A decrease of the reaction rate was observed when using $3 \mathrm{~g} / \mathrm{L}$ of the catalyst. This probably originates from light scattering by the $\mathrm{ZnO}$ :Mn particles, as previously observed for $\mathrm{ZnO}$ materials [47].

The effect of the initial Orange II concentration $(5,10$, or $20 \mathrm{mg} / \mathrm{L})$ on the photocatalytic efficiency was also investigated (Fig. 7b). As can be seen, the photodecomposition rate was found to decrease with the increase of the dye concentration $\left(\mathrm{k}=0.025,0.024\right.$, and $0.003 \mathrm{~min}^{-1}$ for Orange II concentrations of 5, 10 and $20 \mathrm{mg} / \mathrm{L}$, respectively). Since no marked differences were observed during the adsorption phase, the decrease in light penetration by Orange II molecules (filter effect) is probably the cause of this phenomenon.
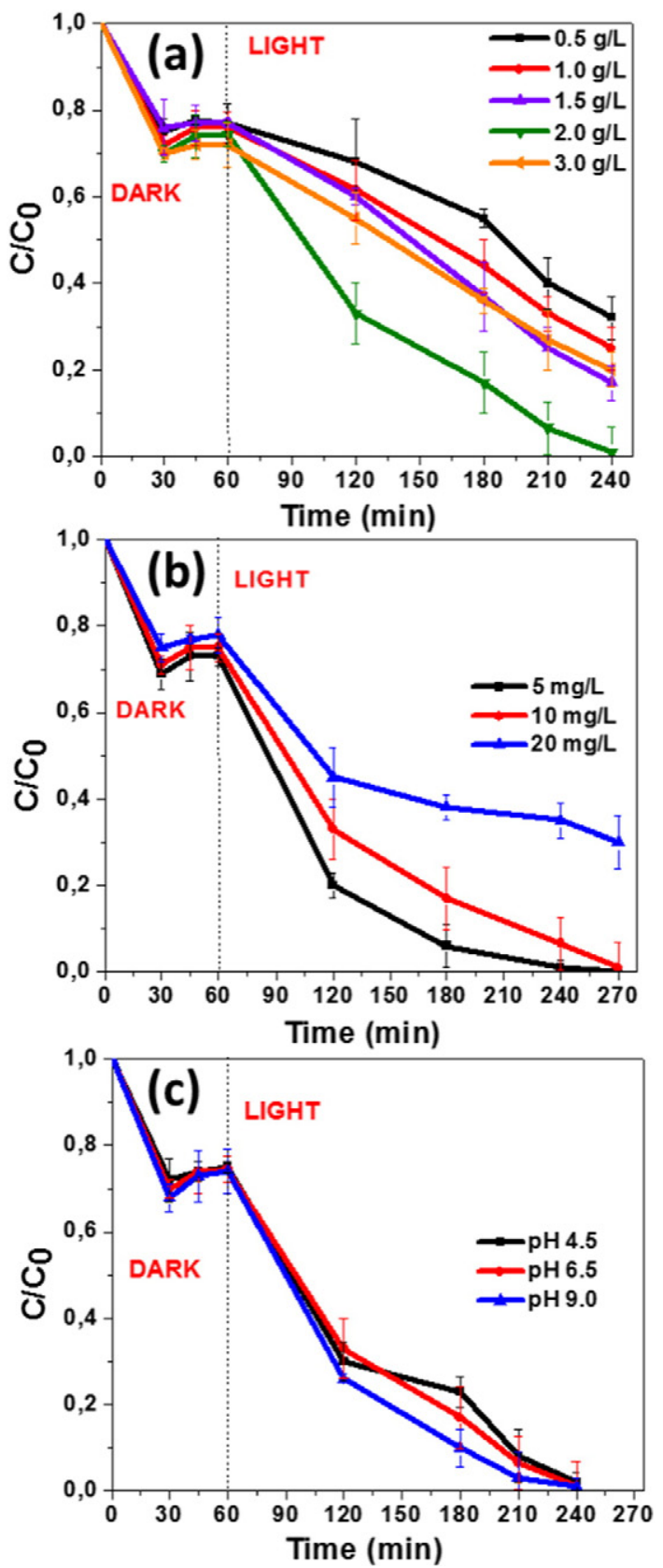

Fig. 7. Influence of (a) the amount of catalyst, (b) the dye concentration and (c) the pH of the Orange II solution on the photocatalytic activity of $\mathrm{ZnO}: \mathrm{Mn}$ (3\%) particles.

The adsorption of the dye at the surface of the catalyst is well-known to depend on the $\mathrm{pH}$ of the solution used [48]. We varied the $\mathrm{pH}$ of the Orange II solution from 4.5 to 9.0 before the adsorption phase and the results are shown in Fig. 7c. No significant differences were observed on the adsorption of the dye. Results obtained show that the optimum $\mathrm{pH}$ for Orange II photodegradation is 9.0 but the photocatalytic activity is not markedly altered at $\mathrm{pH} 6.5$ and 4.5. The later results are of interest since $\mathrm{ZnO}$ is known to exhibit a lower catalytic efficiency at acidic $\mathrm{pH}$ due to its slow dissolution at such $\mathrm{pH}$ values. The initial pseudo-first order rate constants of the $\mathrm{ZnO}: \mathrm{Mn}$ photocatalyst at $\mathrm{pH} 4.5,6.5$, and 9.0 are $0.014,0.017$, and $0.019 \mathrm{~min}^{-1}$, respectively. We attribute the high catalytic activity at $\mathrm{pH}=9$ to the excess of $\mathrm{OH}^{-}$anions that facilitate the photogeneration of $\bullet \mathrm{OH}$, which are well-established as the primary oxidizing species during photocatalytic experiments. 


\subsection{Mechanism}

It is well-known that the photocatalytic efficiency of semiconductor oxides like $\mathrm{ZnO}$ is mainly governed by surface area, defects and surface hydroxyl groups [4-7]. To gain some informations on the mechanism of the photocatalytic degradation, we first measured the specific surface areas and the microporosity of $\mathrm{ZnO}$ and of the $3 \% \mathrm{Mn}^{2+}$-doped $\mathrm{ZnO}$ sample by nitrogen sorption performed at $77 \mathrm{~K}$ (Fig. 8). For both materials, the $\mathrm{N}_{2}$-adsorption-desorption isotherms are of type II, according to the Brunauer-Deming-Deming-Teller (BDDT) classification [49]. A H3-type hysteresis loop can be observed at high relative pressures, characteristic of an adsorbent composed of aggregates, having a non-rigid texture, and indicating the existence of an undefined mesoporosity, which is in good agreement with SEM observations (Fig. S1). ZnO:Mn particles were found to exhibit a higher specific surface area than $\mathrm{ZnO}$ (41.46 and $54.03 \mathrm{~m}^{2} / \mathrm{g}$ for $\mathrm{ZnO}$ and $\mathrm{ZnO}: \mathrm{Mn}$, respectively). The pore size distributions were determined using the Barrett-Joyner-Halenda (BJH) method and are shown in Fig. S6. $\mathrm{ZnO}: \mathrm{Mn}$ particles have a smaller pore size $(23.2 \mathrm{~nm})$ than $\mathrm{ZnO}$ particles $(29.1 \mathrm{~nm})$. These data suggest that the high specific surface area of ZnO:Mn particles may explain the enhancement of the solar-light driven photocatalytic oxidation of Orange II.

For the mineralization of organic dyes by photocatalysis, $\cdot \mathrm{OH}$ radicals are generally considered to have a prominent role as the active species in photodegradation. We therefore compared the production of - $\mathrm{OH}$ radicals upon irradiation of $\mathrm{ZnO}$ and $\mathrm{ZnO}: \mathrm{Mn}$ particles using a fluorescence technique. Hydroxyl radicals are well-known to react with disodium terephthalate (DST) to generate 2-OH-DST which strongly emits fluorescence centered at $428 \mathrm{~nm}$ upon excitation at 312 nm (Fig. 9a) [6,38-40]. As can be seen on Fig. 9b, a gradual increase
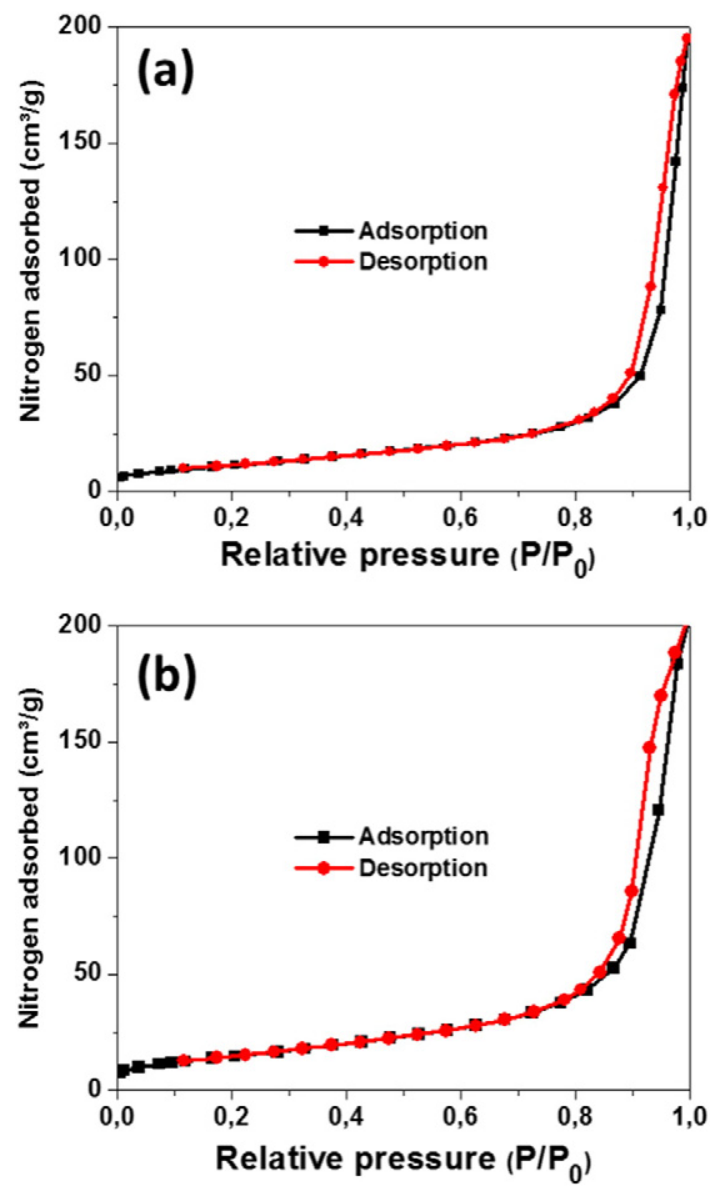

Fig. 8. $\mathrm{N}_{2}$ adsorption-desorption isotherms at $77 \mathrm{~K}$ of $\mathrm{ZnO}$ and $3 \% \mathrm{Mn}^{2+}$-doped $\mathrm{ZnO}$ particles. (a)<smiles>O=C(O[Na])c1ccc(C(=O)O[Na])c([N+](=O)[O-])c1</smiles>

DST

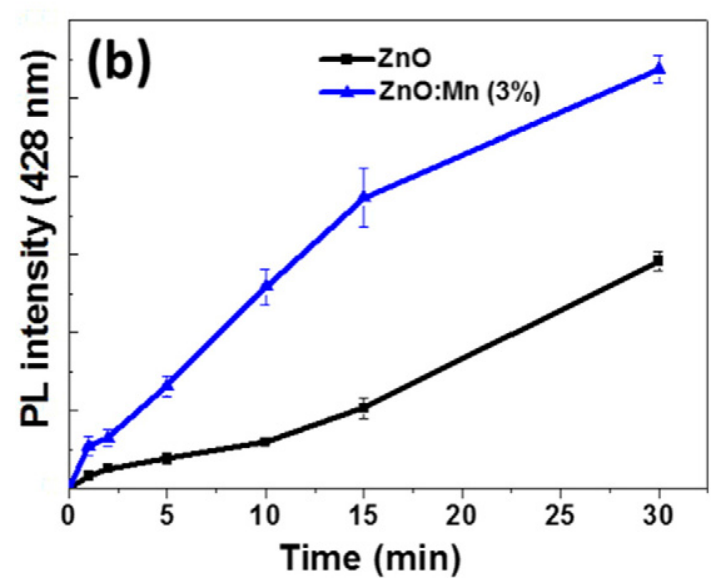

Fig. 9. (a) 2-OH-DST production upon irradiation of DST in the presence of the ZnO photocatalyst. (b) Variations of the PL intensity at $428 \mathrm{~nm}$ of 2-OH-DST upon irradiation of DST with $\mathrm{ZnO}$ and $\mathrm{ZnO}: \mathrm{Mn}(3 \%)$ nanoparticles. Results are the average of three experiments.

in fluorescence intensity at $428 \mathrm{~nm}$ was observed with increasing the irradiation time. The production of $\bullet \mathrm{OH}$ radicals was markedly enhanced when irradiating ZnO:Mn particles. For example, a ca. 3.7-fold increased formation of $\bullet \mathrm{OH}$ radicals was observed for $\mathrm{ZnO}$ :Mn after $15 \mathrm{~min}$ of irradiation compared to the experiment conducted with ZnO (Fig. 9b). Finally, it is worth to mention that 2-OH-DST was not produced in control experiments performed without light irradiation thus confirming a photo-induced mechanism.

The key role played by $\bullet \mathrm{OH}$ radicals during the photocatalytic degradation of Orange II was further confirmed with the use of tert-butyl alcohol $(t-\mathrm{BuOH})$, a chemical scavenger of these radicals [50]. A strong decrease of the photocatalytic degradation rate was observed in the presence of $t-\mathrm{BuOH}$ (Fig. S7). The previous results demonstrate that the higher specific surface of $\mathrm{ZnO}$ :Mn particles associated to the ability of $\mathrm{Mn}^{2+}$ ions to reduce charge recombinations and thus increase $\bullet \mathrm{OH}$ radicals production are beneficial for enhancing the photocatalytic activity.

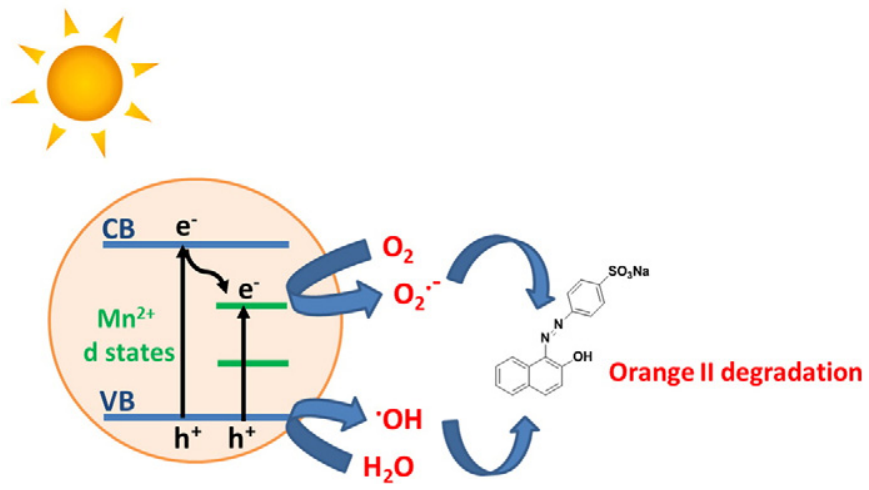

Fig. 10. Schematic illustration of the photocatalytic mechanism of $\mathrm{ZnO}: \mathrm{Mn}$ nanoparticles under solar light irradiation. 


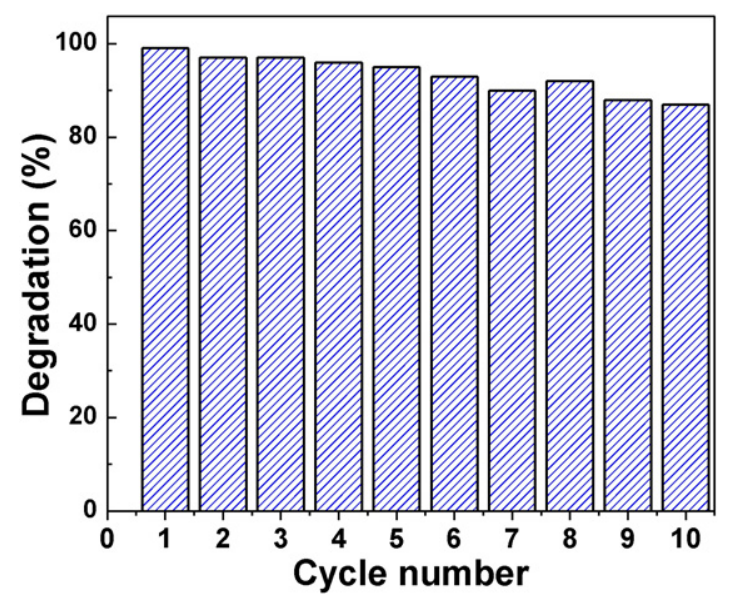

Fig. 11. Plot of photodegradation percent of Orange II using the $\mathrm{ZnO}$ :Mn catalyst at optimized conditions versus cycle number.

The following mechanism can be proposed for the solar light-driven photodegradation of Orange II using ZnO:Mn particles (Fig. 10). Under solar light irradiation, the photogenerated $\mathrm{e}^{-}$can be transferred either to the conduction band ( $\mathrm{CB}$ ) of $\mathrm{ZnO}$ or to $\mathrm{Mn}^{2+}$ energy levels localized within the bandgap of $\mathrm{ZnO}$. Note that electrons promoted to the $\mathrm{CB}$ of $\mathrm{ZnO}$ can also be trapped by the $\mathrm{Mn}^{2+}$ dopant sites. This process inhibits $\mathrm{e}^{-} / \mathrm{h}^{+}$recombinations and allows an enhanced production of ROS. Next, $\mathrm{e}^{-}$react with adsorbed molecular oxygen to yield $\mathrm{O}_{2}{ }^{-}-$radicals. Meanwhile, $\mathrm{h}^{+}$react with surface-bound water to produce $\bullet \mathrm{OH}$ radicals. $\mathrm{O}_{2} \cdot{ }^{-}$and $\bullet \mathrm{OH}$ free radicals, and the reactive species like $\mathrm{HO}_{2} \bullet$ and $\mathrm{H}_{2} \mathrm{O}_{2}$ obtained after association with $\mathrm{H}^{+}$, oxidize Orange II into carbon dioxide and water.

\subsection{Stability}

The stability and the reusability of the $\mathrm{ZnO}: \mathrm{Mn}$ photocatalyst are important parameters in practical applications and were evaluated in ten successive cycles for the degradation of Orange II $(10 \mathrm{mg} / \mathrm{L})$ under solar light irradiation $\left(5 \mathrm{~mW} / \mathrm{cm}^{2}\right)$. After each run, the photocatalyst was recovered by centrifugation ( $4000 \mathrm{rpm}$ for $15 \mathrm{~min}$ ) and redispersed in an Orange II solution without any washing or drying. As shown in Fig. 11, after ten cycles, the photocatalytic efficiency decreased only slightly compared to the as-synthesized $\mathrm{ZnO}$ :Mn particles, thus indicating that the photocatalyst exhibits high stability.

\section{Conclusions}

In summary, we successfully developed a new synthetic route giving access to porous $\mathrm{ZnO}$ and $\mathrm{Mn}$-doped $\mathrm{ZnO}$ particles and which does not require post-synthetic annealing, etching or the use of templates. The influence of the $\mathrm{Mn}^{2+}$ dopant percentage on the structural, optical and photocatalytic properties of $\mathrm{ZnO}: \mathrm{Mn}$ particles was investigated. ZnO:Mn (3\%) exhibit the highest photocatalytic activity for the degradation of Orange II under solar light irradiation. This material exhibits also a higher specific surface compared to pure $\mathrm{ZnO}$. This high specific surface associated to the ability of the $\mathrm{Mn}^{2+}$ dopant to act as an electron trap and to decrease the photogenerated electron/hole pair recombination results in an increase of the $\cdot \mathrm{OH}$ radicals by the $\mathrm{ZnO}: \mathrm{Mn}(3 \%)$ sample and thus of its photocatalytic performances. Moreover, the $\mathrm{ZnO}$ :Mn catalyst can be reused up to ten times with at least $85 \%$ of activity. The synthetic method developed gives an easy and fast access to porous Mn-doped ZnO particles displaying high interest for new technological applications and especially for environmental remediation.

\section{Acknowledgements}

This work is partially supported by the French-Tunisian project PHC Utique CMCU $14 \mathrm{G} 0821$.

\section{Appendix A. Supplementary data}

Supplementary data to this article can be found online at http://dx. doi.org/10.1016/j.matdes.2016.04.015.

\section{References}

[1] S. Dong, J. Feng, M. Fan, Y. Pi, L. Hu, X. Han, M. Liu, J. Sun, J. Sun, Recent developments in heterogeneous photocatalytic water treatment using visible light-responsive photocatalysts: a review, RSC Adv. 5 (2015) 14610-14630.

[2] S. Girish Kumar, K.S.R. Koteswara Rao, Zinc oxide based photocatalysis: tailoring surface-bulk structure and related interfacial charge carrier dynamics for better environmental applications, RSC Adv. 5 (2015) 3306-3351.

[3] N. Shaham-Waldmann, Y. Paz, Photocatalytic reduction of $\mathrm{Cr}(\mathrm{VI})$ by titanium dioxide coupled to functionalized CNTs: an example of counterproductive charge separation, Mater. Sci. Semicond. Process. 42 (2016) 72-80.

[4] C. Hariharan, Photocatalytic degradation of organic contaminants in water by $\mathrm{ZnO}$ nanoparticles, Appl. Catal. A Gen. 304 (2006) 55-61.

[5] C. Tian, Q. Zhang, A. Wu, M. Jiang, Z. Liang, B. Jiang, H. Fu, Cost-effective largescale synthesis of $\mathrm{ZnO}$ photocatalyst with excellent performance for dye photodegradation, Chem. Commun. 48 (2012) 2858-2860.

[6] F. Achouri, S. Corbel, A. Aboulaich, L. Balan, A. Ghrabi, M. Ben Said, R. Schneider, Aqueous synthesis and enhanced photocatalytic activity of $\mathrm{ZnO} / \mathrm{Fe}_{2} \mathrm{O}_{3}$ heterostructures, J. Phys. Chem. Solids 75 (2014) 1081-1087.

[7] H. Moussa, E. Girot, K. Mozet, H. Alem, G. Medjahdi, R. Schneider, ZnO rods/reduced graphene oxide composites prepared via a solvothermal reaction for efficient sunlight-driven photocatalysis, Appl. Catal. B Environ. 185 (2016) 11-21.

[8] V. Jeena, R.S. Robinson, Convenient photooxidation of alcohols using dye sensitised zinc oxide in combination with silver nitrate and TEMPO, Chem. Commun. 48 (2012) 299-301.

[9] F. Wang, L. Liang, L. Shi, M. Liu, J. Sun, $\mathrm{CO}_{2}$-assisted synthesis of mesoporous carbon/C-doped $\mathrm{ZnO}$ composites for enhanced photocatalytic performance under visible light, Dalton Trans. 43 (2014) 16441-16449.

[10] S. Anandan, M. Miyauchi, Ce-doped $\mathrm{ZnO}\left(\mathrm{Ce}_{\mathrm{x}} \mathrm{Zn}_{1}-{ }_{\mathrm{x}} \mathrm{O}\right)$ becomes an efficient visiblelight-sensitive photocatalyst by co-catalyst $\left(\mathrm{Cu}^{2+}\right)$ grafting, Phys. Chem. Chem. Phys. 13 (2011) 14937-14945.

[11] M. Ahmad, E. Ahmed, Y. Zhang, N.R. Khalid, J. Xu, M. Ullah, Z. Hong, Preparation of highly efficient Al-doped $\mathrm{ZnO}$ photocatalyst by combustion synthesis, Curr. Appl. Phys. 13 (2013) 697-704.

[12] R. Mohan, K. Krishnamoorthy, S.-J. Kim, Enhanced photocatalytic activity of Cu-doped ZnO nanorods, Solid State Commun. 152 (2012) 375-380.

[13] J.Z. Bloh, R. Dillert, D.W. Bahnemann, Transition metal-modified zinc oxides for UV and visible light photocatalysis, Environ. Sci. Pollut. Res. 19 (2012) 3688-3695.

[14] S.C. Erwin, L. Zu, M.I. Haftel, A.L. Efros, T.A. Kennedy, D.J. Norris, Doping semiconductor nanocrystals, Nature 436 (2005) 91-94.

[15] D.J. Norris, A.L. Efros, S.C. Erwin, Doped nanocrystals, Science 319 (2008) 1776-1779.

[16] R. Ullah, J. Dutta, Photocatalytic degradation of organic dyes with manganese-doped ZnO nanoparticles, J. Hazard. Mater. 156 (2008) 194-200.

[17] K. Rekha, M. Nirmala, M.G. Nair, A. Anukaliani, Structural, optical, photocatalytic and antibacterial activity of zinc oxide and manganese doped zinc oxide nanoparticles, Physica B 405 (2010) 3180-3185.

[18] M. Abbas Mahmood, S. Baruah, J. Dutta, Enhanced visible light photocatalysis by manganese doping or rapid crystallization with $\mathrm{ZnO}$ nanoparticles, Mater. Chem. Phys. 130 (2011) 531-535.

[19] D. Zhang, Structural, optical, electrical, and photocatalytic properties of manganese doped zinc oxide nanocrystals, Russ. J. Phys. Chem. A 86 (2012) 93-99.

[20] Y. Yang, Y. Li, L. Zhu, H. He, L. Hu, J. Huang, F. Hu, B. He, Z. Ye, Shape control of colloidal $\mathrm{Mn}$ doped $\mathrm{ZnO}$ nanocrystals and their visible light photocatalytic properties, Nanoscale 5 (2013) 10461-10471.

[21] R. Saleh, N.F. Djaja, Transition-metal-doped ZnO nanoparticles: synthesis, characterization and photocatalytic activity under UV light, Spectrochim. Acta A 130 (2014) 581-590.

[22] K. Umar, A. Aris, T. Parveen, J. Jaafar, Z.A. Majid, A.V. Bhaskar Reddy, J. Talib, Synthesis, characterization of Mo and Mn doped $\mathrm{ZnO}$ and their photocatalytic activity for the decolorization of two different chromophoric dyes, Appl. Catal. A Gen. 505 (2015) 507-514.

[23] X. Wu, K.W. Li, H. Wang, Facile fabrication of porous $\mathrm{ZnO}$ microspheres by thermal treatment of ZnS microspheres, J. Hazard. Mater. 174 (2010) 573-580.

[24] Y. Du, R.Z. Chen, J.F. Yao, H.T. Wang, Facile fabrication of porous ZnO by thermal treatment of zeolitic imidazolate framework-8 and its photocatalytic activity, J. Alloys Compd. 551 (2013) 125-130.

[25] Z.D. Li, Y. Zhou, G.G. Xue, T. Yu, J.G. Liu, Fabrication of hierarchically assembled microspheres consisting of nanoporous $\mathrm{ZnO}$ nanosheets for high-efficiency dye-sensitized solar cells, J. Mater. Chem. 22 (2012) 14341-14345.

[26] W.L. Ong, S. Natarajan, B. Kloostra, G.W. Ho, Metal nanoparticle-loaded hierarchically assembled $\mathrm{ZnO}$ nanoflakes for enhanced photocatalytic performance, Nanoscale 5 (2013) 5568-5575. 
[27] Z.J. Xing, B.Y. Geng, X.L. Li, H. Jiang, C.X. Feng, Self-assembly fabrication of 3D porous quasi-flower-like $\mathrm{ZnO}$ nanostrip clusters for photodegradation of an organic dye with high performance, CrystEngComm 13 (2011) 2137-2142.

[28] T. Kimuro, Y. Yamauchi, N. Miyamoto, Condensation- and crystallinity-controlled synthesis of titanium oxide films with assessed mesopores, Chem. Eur. J. 16 (2010) 12069-12073.

[29] Z. Jing, J. Zhan, Fabrication and gas-sensing properties of porous ZnO nanoplates, Adv. Mater. 20 (2008) 4547-4551.

[30] M. Chen, Z. Wang, D. Han, F. Gu, G. Guo, Porous ZnO polygonal nanoflakes: synthesis, use in high-sensitivity $\mathrm{NO}_{2}$ gas sensor, and proposed mechanism of gas sensing, J. Phys. Chem. C 115 (2011) 12763-12773.

[31] H. Wang, G. Li, L. Jia, G. Wang, C. Tang, Controllable preferential-etching synthesis and photocatalytic activity of porous ZnO nanotubes, J. Phys. Chem. C 112 (2008) 11738-11743.

[32] X. Liu, J. Zhang, L. Wang, T. Yang, X. Guo, S. Wu, S. Wang, 3D hierarchically porous $\mathrm{ZnO}$ structures and their functionalization by Au nanoparticles for gas sensors, J. Mater. Chem. 21 (2011) 349-356.

[33] F. Xu, P. Zhang, A. Navrotsky, Z.-Y. Yuan, T.-Z. Ren, M. Halasa, B.-L. Su, Hierarchically assembled porous $\mathrm{ZnO}$ nanoparticles: synthesis, surface energy, and photocatalytic activity, Chem. Mater. 19 (2007) 5680-5686.

[34] Z. Deng, M. Chen, G. Gu, L. Wu, A facile method to fabricate ZnO hollow spheres and their photocatalytic property, J. Phys. Chem. B 112 (2008) 16-22.

[35] M. Chen, L. Hu, J. Xu, M. Liao, L. Wu, X. Fang, ZnO hollow-sphere nanofilm-based high-performance and low-cost photodetector, Small 7 (2011) 2449-2453.

[36] X. Wu, K. Li, H. Wang, Facile fabrication of porous $\mathrm{ZnO}$ microspheres by thermal treatment of ZnS microspheres, J. Hazard. Mater. 174 (2010) 573-580.

[37] G. Zhang, Y. Shen, Y. Yang, Facile synthesis of monodisperse porous ZnO spheres by a soluble starch-assisted method and their photocatalytic activity, J. Phys. Chem. C 115 (2011) 7145-7152.

[38] C. Bohne, K. Faulhaber, B. Giese, A. Hafner, A. Hofmann, H. Ihmels, A.-K. Kohler, S. Pera, F. Schneider, M.A.L. Sheepwash, Studies on the mechanism of the photoinduced dan damage in the presence of acridizinium salts involvement of singlet oxygen and an unusual source for hydroxyl radicals, J. Am. Chem. Soc. 127 (2005) 76-85.
[39] Y. Iida, K. Yasui, T. Tuziuti, M. Sivakumar, Y. Endo, Ultrasonic cavitation in microspace, Chem. Commun. 2280-2281 (2004).

[40] H. Sies, Oxidative stress: Oxidants and antioxydants, Exp. Physiol. 82 (1997) 291-295.

[41] K.A. Alim, V.A. Fonobarov, M. Shamsa, A.A. Balandin, Micro-Raman investigation of optical phonons in ZnO nanocrystals, J. Appl. Phys. 97 (2005) 124313.

[42] L.F. Koao, F.B. Dejene, H.C. Swart, J.R. Botha, The effect of $\mathrm{Ce}^{3+}$ on structure morphology and optical properties of flower-like $\mathrm{ZnO}$ synthesized using the chemical bath method, J. Lumin. 143 (2013) 12-17.

[43] M.I. Dar, N. Arora, N.P. Singh, S. Sampath, S.A. Shivashankar, Role of spectator ions in influencing the properties of dopant-free ZnO nanocrystals, New J. Chem. 38 (2014) 4783-4790.

[44] H. Moussa, C. Merlin, C. Dezanet, L. Balan, G. Medjahdi, M. Ben-Attia, R. Schneider, Trace amounts of $\mathrm{Cu}^{2+}$ ions influence ROS production and cytotoxicity of $\mathrm{ZnO}$ quantum dots, J. Hazard. Mater. 304 (2016) 532-542.

45] X. Yan, D. Hu, H. Li, L. Li, X. Chong Y. Wang, Nanostructure and optical properties of M doped $\mathrm{ZnO}(\mathrm{M}=\mathrm{Ni}, \mathrm{Mn})$ thin films prepared by sol-gel process, Physica B 406 (2011) 3956-3962.

46] S. Yilmaz, S. Garry, E. Mc Glynn, E. Bacaksiz, Synthesis and characterization of Mn-doped $\mathrm{ZnO}$ nanorods grown in an ordered periodic honeycomb pattern using nanosphere lithography, Ceram. Int. 40 (2014) 7753-7759.

[47] B. Subash, B. Krishnakumar, R. Velmurungen, M. Swiminathan, M. Shanti, Synthesis of Ce co-doped Ag-ZnO photocatalyst with excellent performance for NBB dye degradation under natural sunlight illumination, Catal. Sci. Technol. 2 (2012) 2319-2326.

[48] R. Velmuragan, M. Swaminathan, An efficient nanostructured $\mathrm{ZnO}$ for dye sensitized degradation of Reactive Red 120 dye under solar light, Sol. Energy Mater. Sol. Cells 95 (2011) 942-950.

[49] K. Singh, D. Everett, R. Paul, L. Moscou, R. Pierotti, J. Rouquerol, T. Siemieniewska, Reporting physisorption data for gas/solid systems with special reference to the determination of surface area and porosity, Pure Appl. Chem. 57 (1985) 603-619.

[50] Y. Ou, J.D. Lin, H.M. Zou, D.W. Liao, Effects of surface modification of $\mathrm{TiO}_{2}$ with ascorbic acid on photocatalytic decolorization of an azo dye reactions and mechanisms, J. Mol. Catal. A Chem. 241 (2005) 59-64. 